\title{
Study of the Effect of the Rate of Flow of Carbon Dioxide Gas for Creation of Pneumoperitoneum on Cardiovascular System during Laparoscopic Surgeries
}

\author{
Dr. Sucheta Bhowate Meshram ${ }^{* 1}$, Dr. Sandhya Gujar², Dr. Karuna Sidam³, \\ Dr. Tanumoy Maulick, Junior Resident ${ }^{4}$ \\ ${ }^{* 1}$ Associate Professor, Department of Anaesthesiology, ESI-PGIMSR MODEL HOSPITAL CUM O.D.C \\ ${ }^{2}$ Professor \& HOD, Department of Anaesthesiology, ESI-PGIMSR MODEL HOSPITAL CUM O.D.C \\ ${ }^{3,4}$ Department of Anaesthesiology, ESI-PGIMSR MODEL HOSPITAL CUM O.D.C
}

Abstract: Laparoscopy has gained a worldwide acceptance due to its added advantages. Pneumoperitoneum required for this although aids in the surgical skill but invites a straight challenge to the attending anaesthesiologist for optimal control of haemodynamics.Reports of serious complication have been documented with abrupt and rough insufflation techniques of artificial creation of pneumoperitoneum ranging from mild bradycardia to frank cardiac arrest due to vagal mediated parasympathetic response due to rapid stretching of peritoneum. Gradual, gentle and slow rate of insufflation can prevent such complications. In this context, we have conducted a study on 40 patients of ASA I and ASA II, undergoing elective laparoscopic surgery requiring general anaesthesia with intubation. Patients were randomly allocated into study (A) and control (B) group. Group A (20 patients) comprises of the group where surgeon uses gradual and slow rate of insufflations of co2 whereas group $B$ comprises of patients in which the surgeons uses abrupt and rapid insufflations of co2 at the rate of more than 4L/min and have found statistically significant hemodynamic changes in group $B$ in comparison to Group A. Hence, we have concluded that insufflation with high flow rate while establishing artificial pneumoperitoneum increase IAP instantaneously and unexpected cardiovascular changes occurs such as hypotension, bradyarrhythmia whereas slow rate of insufflations prevents such complications. In patients with compromised cardio respiratory status, such vagal response with abrupt and rapid insufflations of co2 can prove to be detrimental.Therefore, not only maintaining IAP below 12-15 mmHg but also keeping slow insufflation rate (2-4lit/min) when establishing pneumoperitoneum is important and essential.

Keywords: Laparoscopy, Pneumoperitoneum, Rate of insufflations.

\section{INTRODUCTION:}

Laparoscopy has made its place in the present era and has achieved world wide acceptance .It has made a tremendous impact on the field of anaesthesia. It has various advantages over the open technique including small incision, reduced pain, better cosmetic result, quicker recovery, reduced hospital stay, lesser post operative complications etc. Though considered a gentle surgery, the procedure is indeed not risk free, because of the increased abdominal pressure due to "Pneumoperitoneum", which has significant haemodynamic and respiratory effect.[1,2,14,15]

Pneumoperitoneum creation using carbon dioxide $\left(\mathrm{CO}_{2}\right)$ is used to assist laparoscopic surgery by distending abdominal cavity and splitting up its content, which improves visualization. Carbon dioxide is the most commonly used insufflation agent amongst the various other gases, as it is highly soluble in the blood and its elimination can be augmented by increasing the minute ventilation. Due to the decreased lung compliance 
and insufficient ventilation, uptake of carbon dioxide from pneumoperitoneum can cause hypercarbia and respiratory acidosis.[5,6 10,11,12] Alongwith the physiological effect of carbon dioxide per se, pneumoperitoneum and increased intra abdominal pressure can induce many pathophysiological disturbances, requiring the anesthesiologist to be well alert during the operation for necessary management. Moreover advanced laparoscopic surgeries are being used also on older patients and in critically ill patients, requiring technically demanding anaesthesia. In addition, highflow insufflations, high insufflation pressures, profound hypercarbia and interplay of potentially lethal anaesthetic medications have also been implicated in cardiovascular changes. Hence it is necessary to learn the ideal rate of insufflations of $\mathrm{co} 2$ for creation of pneumoperitoneum to prevent such catastrophic consequences. [3]

\section{AIMS AND OBJECTIVES:}

This study aims to observe the effect of rate of flow of insufflations of carbon dioxide for creating pneumoperitoneum on cardiovascular changes in patient of ASA grade1 and 2 posted for elective laparoscopic surgery under general anaesthesia.

Hemodynamic and respiratory parameter, including
A) Heart rate
b) Blood pressure
c) End tidal co2 were observed.

\section{MATERIAL AND METHODS:}

40 patients undergoing elective surgery requiring general anaesthesia with intubation were randomly allocated into study group [A] of 20 patients and control group [B] of 20 patients Cases have been categorized into groups mentioned above according to the surgeons who prefer abrupt and rapid insufflations and those who tend to insufflate gently and at slower rate.

\section{ELIGIBILITY CRITERIA}

\section{A) Inclusion criteria}

1) age between $20-60 \mathrm{yrs}$

2) patients classified under ASA grade I and II

3) MPC grade I and II

\section{B) Exclusion criteria}

1) Patients classified as ASAIII and IV

2) Preexisting respiratory or cardiac disease

3) MPC > grade II

4) Pregnant patients

5) Pediatric age group

6) Morbidly obese patients

7) Procedure-related intra-operative complications including puncture of hollow viscus and major vessels, haemorrhage, pneumomediastinum, pneumothorax, subcutaneous emphysema, gas embolism and cardiac tamponade were excluded as the primary reason for causing haemodynamic instability in our patients.

\section{OBSERVATIONS:}

Table No 1: GROUPWISE DISTRIBUTION:

\begin{tabular}{|c|l|l|}
\hline GROUP & & NO OF PATIENTS \\
\hline $\mathrm{A}$ & STUDY GROUP & 20 \\
\hline $\mathrm{B}$ & CONTROL GROUP & 20 \\
\hline
\end{tabular}


Fig No. 1: Groupwise Distribution

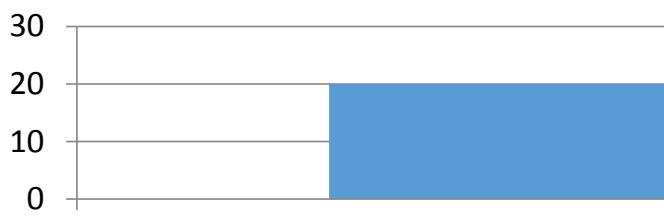

Group A
Group B

Table No 2: DEMOGRAPHIC CHARACTERISTICS:

\begin{tabular}{|l|l|l|l|}
\hline PARAMETERS & GROUP A & GROUP B & Intergroup P \\
\hline AGE & $41.27+/$ 7.33(26-54) & $42.04+/ 7.72(29-53)$ & $>0.05$ \\
\hline GENDER & & & \\
\hline \multicolumn{1}{|c|}{ Male } & $3(15 \%)$ & $6(30 \%)$ & \\
\hline \multicolumn{1}{|c|}{ Female } & $17(85 \%)$ & $14(70 \%)$ & \\
\hline WEIGHT(kg) & $55.25+/ 8.46(44-68)$ & $55.95+/ 6.36(45-69)$ & $>0.05$ \\
\hline ASA & & & \\
\hline 1 & $14(70 \%)$ & $12(60 \%)$ & $>0.05$ \\
\hline 2 & $6(30 \%)$ & $8(40 \%)$ & \\
\hline
\end{tabular}

Above parameters are statistically comparable.

\section{Table No 3: EFFECT ON HEART RATE}

\begin{tabular}{|l|l|l|l|l|l|l|l|l|l|l|}
\hline \multirow{2}{*}{$\begin{array}{l}\text { STUDY } \\
\text { PARAMETER }\end{array}$} & \multicolumn{5}{|c|}{ Group A } & \multicolumn{3}{c|}{ Group B } & $\begin{array}{l}\text { Unpaire } \\
\text { d'T' } \\
\text { test }\end{array}$ & $\begin{array}{l}\text { P } \\
\text { Value }\end{array}$ \\
\cline { 2 - 11 } & Mean & Std dev & Median & IQR & Mean & Std.dev & Median & IQR & \\
\hline HR BASELINE & 84.73 & 12.19 & 84.00 & 16 & 80.97 & 10.29 & 80.00 & 16.00 & 1.293 & 0.2 \\
\hline $\begin{array}{l}\text { JUST AFTER } \\
\text { INTUBATION }\end{array}$ & 92.47 & 9.8 & 91.50 & 14 & 97.4 & 13.52 & 96 & 16 & -1.195 & 0.23 \\
\hline $\begin{array}{l}1 \text { MIN AFTER } \\
\text { INSUFFLATION }\end{array}$ & 94.33 & 10.43 & 94 & 14 & 78.2 & 9.58 & 75 & 9.00 & -5.918 & 0.00 \\
\hline $\begin{array}{l}\text { 3 MIN AFTER } \\
\text { INSUFFLATION OF } \\
\text { CO2 }\end{array}$ & 90.07 & 10.66 & 91 & 13 & 76.3 & 6.42 & 74 & 8 & -10.462 & 0.00 \\
\hline $\begin{array}{l}\text { 5MIN AFTER } \\
\begin{array}{l}\text { INSUFFLATION OF } \\
\text { CO2 }\end{array}\end{array}$ & 91.6 & 9.8 & 91.9 & 14 & 77.12 & 8.43 & 74.6 & 8 & -5.9 & 0.00 \\
\hline $\begin{array}{l}\text { 10 MIN AFTER } \\
\text { INSUFFLATION OF } \\
\text { CO2 }\end{array}$ & 98.63 & 8.56 & 94.2 & 7 & 81.7 & 11.9 & 78.5 & 12 & -6.9 & 0.00 \\
\hline
\end{tabular}

$\mathrm{P}$ value $<0.05$-statistically significant for the heart rate after insufflations of co2. 
Fig No. 2: Effect on Heart Rate

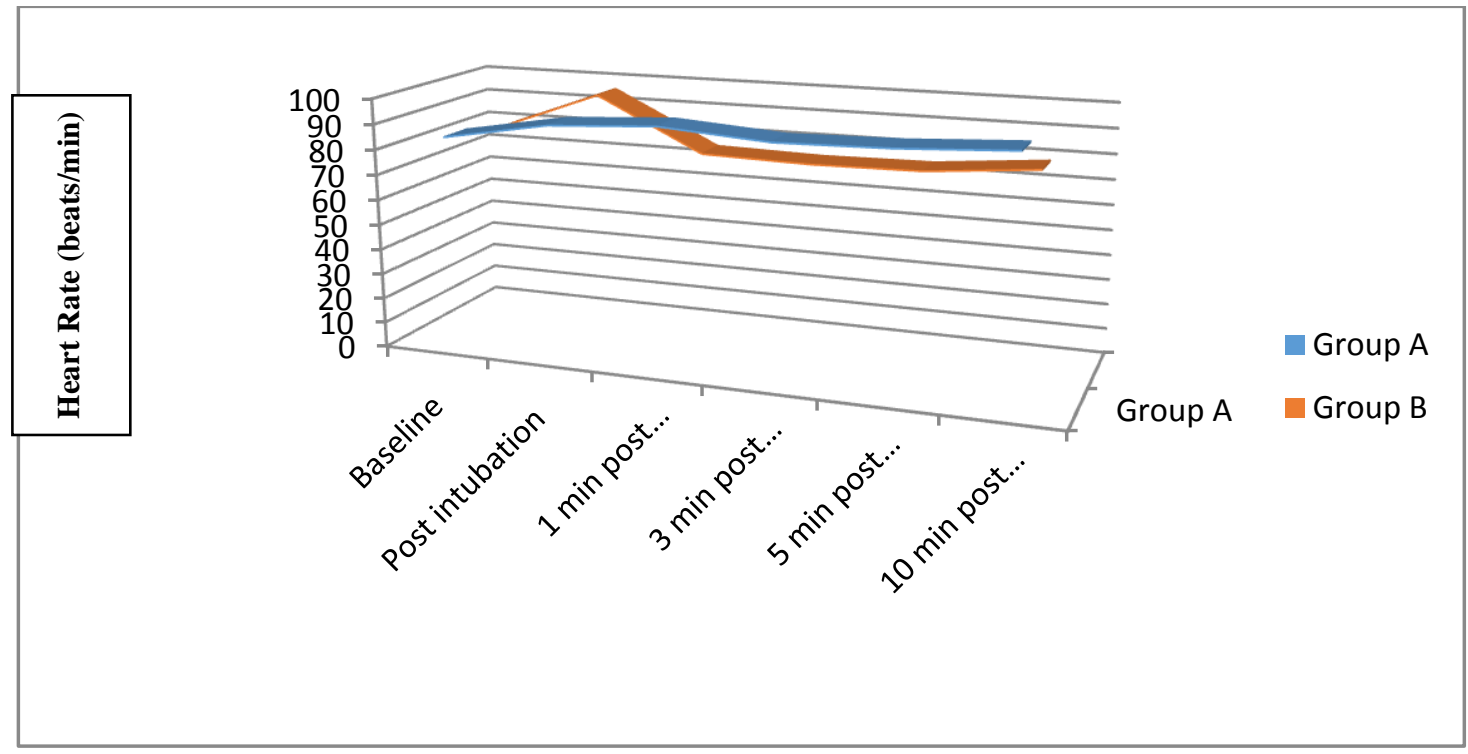

Table No 4: EFFECT ON MEAN ARTERIAL PRESSURE:

\begin{tabular}{|c|c|c|c|c|c|c|c|c|c|c|}
\hline \multirow[t]{2}{*}{ STUDY PARAMETERS } & \multicolumn{4}{|c|}{ Group A } & \multicolumn{4}{|c|}{ Group B } & \multirow{2}{*}{$\begin{array}{l}\text { Unpaired } \\
\text { ' } \mathrm{T} \text { ' Test }\end{array}$} & \multirow[t]{2}{*}{$\mathrm{P}$ value } \\
\hline & Mean & $\begin{array}{l}\text { Std. } \\
\text { dev }\end{array}$ & Median & IQR & Mean & $\begin{array}{l}\text { Std. } \\
\text { dev }\end{array}$ & Median & IQR & & \\
\hline BASELINE & 89.3 & 7.4 & 92 & 15 & 92.14 & 5.4 & 94.17 & 6.00 & 1.886 & 0.06 \\
\hline $\begin{array}{l}\text { IMMEDIATE AFTER } \\
\text { INTUBATION }\end{array}$ & 102.7 & 11 & 100.2 & 20 & 94.6 & 5.67 & 94.3 & 10.00 & -6.2 & 0.02 \\
\hline $\begin{array}{l}\text { 1MIN AFTER } \\
\text { INSUFFLATION OF } \\
\mathrm{CO} 2\end{array}$ & 101.2 & 13.3 & 100.5 & 21 & 84.5 & 8.0 & 84.4 & 10 & -5.5 & 0.00 \\
\hline $\begin{array}{l}3 \text { MIN AFTER } \\
\text { INSUFFLATION OF } \\
\mathrm{CO} 2\end{array}$ & 94.2 & 12.2 & 95 & 17 & 82.4 .5 & 6 & 83.1 & 10 & -3.6 & 0.00 \\
\hline $\begin{array}{l}5 \text { MIN AFTER } \\
\text { INSUFFLATION OF } \\
\mathrm{CO} 2\end{array}$ & 89.33 & 12 & 92.3 & 22 & 80.7 & 4.7 & 80.2 & 7.0 & -3.4 & 0.00 \\
\hline $\begin{array}{l}10 \text { MIN AFTER } \\
\text { INSUFFLATION OF } \\
\mathrm{CO} 2\end{array}$ & 88.9 & 12.9 & 89 & 17 & 82.2 & 5.2 & 79 & 7.03 & -3.09 & 0.00 \\
\hline
\end{tabular}

$P$ value $<0.05$ - statistically significant 


\section{Figure No 3: EFFECT ON MEAN ARTERIAL PRESSURE}

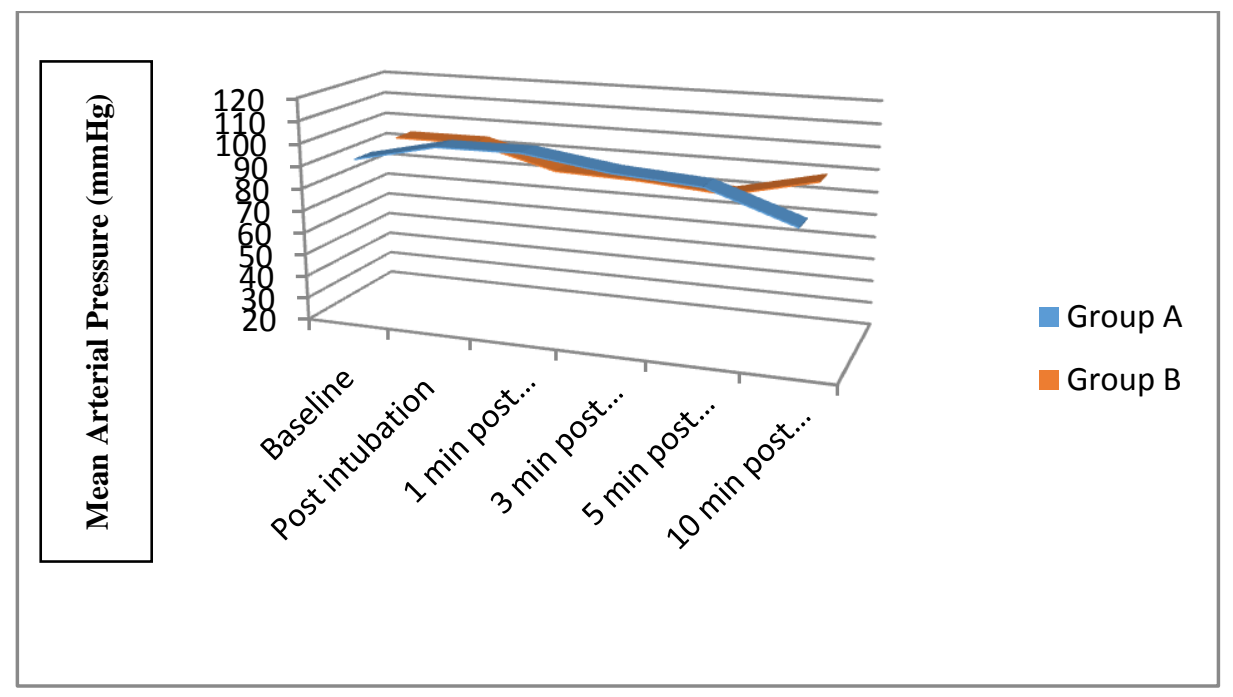

Table No 5: ETCO2 :

\begin{tabular}{|c|c|c|c|}
\hline ETCO2 & $28-35$ & $36-40$ & $>40$ \\
\hline GROUPS & & & \\
\hline A & 16 & 4 & 0 \\
\hline B & 17 & 2 & 1 \\
\hline TOTAL & 33 & 6 & 1 \\
\hline
\end{tabular}

$\mathrm{P}>0.05$.so both the groups are comparable.

Table No 6: RESCUE MEDICATIONS:

\begin{tabular}{|c|c|}
\hline GROUPS & NO OF PATIENTS WHO REQUIRED RESCUE MEDICATION \\
\hline $\mathrm{A}$ & $0(0 \%)$ \\
\hline $\mathrm{B}$ & $2(10 \%)$ \\
\hline
\end{tabular}

$\mathrm{P}<0.05$ significant difference

\section{RESULTS:}

Statistical analysis revealed that there was significant difference between study group and control group in terms of heart rate and mean arterial pressure .Results shows that the group in which the rate of insufflation of carbon dioxide was $2-4 \mathrm{~L} / \mathrm{min}$, heart rate and mean arterial pressure were stable whereas in control group where abrupt and rapid insufflations done, significant decrease in heart rate and mean arterial pressure was observed. Other demographic parameters were statistically comparable.

\section{DISCUSSION:}

Laparoscopy has gained a worldwide acceptance due to its added advantages. Pnemoperitoneum required for this although aids in the surgical skill but invites a straight challenge to the attending anaesthesiologist for optimal control of haemodynamics .Reports of serious complication have been documented with abrupt and rough 
insufflations techniques even prior start of surgery. The complication ranges from mild bradycardia [1] to frank cardiac arrest [6]. It is well known that laparoscopic surgery, using $\mathrm{CO}_{2}$ to make a pneumoperitoneum, has risks of pathophysiological cardiovascular changes, such as severe bradycardia, arrhythmia, and cardiac arrest requiring cardiopulmonary resuscitation [1]. Causes of such alteration are known to be associated with vagal-mediated cardiovascular reflex initiated by rapid peritoneum distension due to insufflation or gas embolism [2]. Limiting of intra-abdominal pressure (IAP) below 12-15 $\mathrm{mmHg}$ during insufflation is known to be effective to prevent pathophysiological changes of pneumoperitoneum [1].

Even though pressure limitations of insufflator if limited to $12 \mathrm{mmHg}$ in, severe bradycardia can develop with rapid and abrupt insufflation technique [1]. Gas embolism was ruled out because there were no changes in $\mathrm{ETCO}_{2}$ and $\mathrm{SpO}_{2}$ [1]. Arrhythmias that developed after rapid stretching of peritoneum are transient and responded well to reduction of IAP [2], and our patients had recovered soon after stopping insufflations and hyperventilation with $100 \% \mathrm{O}_{2}$; thus, we concluded the arrhythmias are a consequence of peritoneal distension due to rapid increase of IAP after $\mathrm{CO}_{2}$ insufflation with high flow rate. But, it was a question that how high flow rate of insufflator could affect the IAP in the circumstances of maintaining acceptable pressure limit. Insufflator works effectively when balance of pressure, resistance and flow in system is established. Accordingly, gas flow from insufflator patient's abdomen follows the HagenPoiseuille's law theoretically [3]:

$$
\mathrm{V}=\frac{\pi \times r^{4}}{8 \times \eta \times 1} \times \Delta P
$$

Where $\mathrm{V}=$ gas flow, $\pi=$ factor $\mathrm{Pi}, \mathrm{r}=$ radius, $8=$ constant, $\eta=$ viscosity, $1=$ length, and $\Delta \mathrm{P}=$ pressure difference.

The Hagen-Poiseuille's law states, gas flow rises in proportion to a rise in pressure, and depends on the smallest diameter of the system [3,4]. Thus, pressure will rise when gas passes at high flow rate through high resistance channel of trocar, such as luer lock connector. Consequently, IAP will rise quickly if insufflator is regulated to keep a high flow rate as $20 \mathrm{~L} / \mathrm{min}$ from the start of pneumoperitoneum. And more, insufflator that supports high flow rate usually uses over-pressure insufflation principle, which puts pressure much greater than preset value when starting insufflation [3].

Over-pressure system supply pressure beyond the preset value when starting of pneumoperitoneum and pressure decreased during insufflation break intermittently, until IAP reaches to the nominal pressure that has usually been preset to $12 \mathrm{mmHg}$ $[3,4]$. As such, even if the preset value is limited to $12 \mathrm{mmHg}$, peak pressure of IAP will exceed the limit in an instant to keep up the fixed flow rate. Such repetitive exceeded IAP may stretch the peritoneum and stimulate vagal responses. We have concluded that insufflation with high flow rate when establishing artificial pneumoperitoneum may increase IAP instantaneously and unexpected cardiovascular changes, such as hypotension, bradyarrhythmia may occur whereas slow rate of insufflations prevents such complications .Our study was done in ASA I and ASA II where no pre existing significant comorbidity was present. In patients with compromised cardiorespiratory status, such vagal response with abrupt and rapid insufflations of $\operatorname{co} 2$ can prove to be detrimental[5] Therefore, not only maintaining IAP below $12-15 \mathrm{mmHg}$, [10] but also keeping slow insufflation when establishing pneumoperitoneum is important and essential. It is observed that slow and gradual 
insufflations prevent the vagal mediated bradyarrthmia, hypotension and its sequele.

In addition, highflow insufflations, high insufflation pressures, hypovolemia, venous gas embolism, myocardial dysfunction, myocardial ischemia, cardiac dysrhythmias, tension pneumothorax, pneumomediastinum, subcutaneous emphysema, profound hypercarbia and interplay of potentially lethal anaesthetic medications have also been implicated in cardiac arrest. Meticulous monitoring was done with utmost vigilance. All the above possibilities were ruled out $[8,11,12]$

Procedure-related intra-operative complications including puncture of hollow viscus and major vessels, haemorrhage, pneumomediastinum, pneumothorax, subcutaneous emphysema and cardiac tamponade were also excluded as the primary reason for causing cardiac complications in our patients, concluded from our clinical observations

\section{CONCLUSION:}

Insufflation with high flow rate when establishing artificial pneumoperitoneum may increase IAP instantaneously and unexpected cardiovascular changes, such as hypotension, bradyarrhythmia or cardiac arrest, may occur. Therefore, not only maintaining IAP below $12 \mathrm{mmHg}$ [16], but also keeping slow insufflation $[3,5]$ when establishing pneumoperitoneum is important and essential. Hence rate of insufflations of etco 2 is recommended to be $2-41 / \mathrm{min}$ and not more than that.

\section{REFERENCES:}

1) Cho EJ, Min TK. Cardiac arrest after gas insufflation for laparoscopic surgery: two case reports. Korean J Anesthesiol. 2005; 49:712715.
2) Myles PS. Bradyarrhythmias and laparoscopy: a prospective study of heart rate changes with laparoscopy. Aust N Z J Obstet Gynaecol. 1991; 31:171-173.

3) Jacobs VR, Morrison JE, Jr, Kiechle M. Twenty-five simple ways to increase insufflation performance and patient safety in laparoscopy. J Am Assoc Gynecol Laparosc. $2004 ; 11: 410-423$.

4) Jacobs VR, Morrison JE, Jr, Paepke S, Fischer $\mathrm{T}$, Kiechle M. Three-dimensional model for gas flow, resistance, and leakage-dependent nominal pressure maintenance of different laparoscopic insufflators. J Minim Invasive Gynecol. 2006; 13:225-230.

5) Dhoste K, Lacoste L, Karayan J, Lehuede MS, Thomas D, Fusciardi J. Haemodynamic and ventilatory changes during laparoscopic cholecystectomy in elderly ASA III patients. Can J Anaesth. 1996; 43:783-788.

6) Gautam B,Shrestha BR et al.Cardiac arrest during laproscopic cholecystectomy under general anaestesia:A study in four cases.kathmandu University Medical Journal(2009),vol.7,No.3,Issue 27,280-288

7) Qianlin Zhu,Zhihai Mao,Buwei Yu,Jue Jin JOURNAL OF LAPAROENDOSCOPIC \& ADVANCED SURGICAL TECHNIQUES Volume 19, Number 5, 2009,611-14;

8) Catherine M. Wittgen. Charles H. Andrus. Stephen D. Fitzgerald, Lawrence 3. Baudendistel, Thomas E. Dahrns. Donald L. Kaminsk et al. Analysis of the Hemodynamic and Ventilatory Effects of Laparoscopic Cholecystectomy. Arch Surg $1991 ; 126: 997-$ 01 
9) Dexter SP, Vucevic M, Gibson J, McMahon MJ. Hemodynamic consequences of high- and low-pressure capnoperitoneum during laparoscopic cholecystectomy. Surg Endosc 1999; 13:376-381.

10) Joris JL, Noirot DP, Legrand MJ, Jacquet NJ, Lamy ML. Hemodynamic changes during laparoscopic cholecystectomy. Anesth Analg 1993; 75: 1067-1071.

11) Nguyen NT, Anderson J, Fleming NW, et al. Effects of pneumoperitoneum on intraoperative respiratory mechanics and gas exchange during laparoscopic gastric bypass. Surg Endosc (2010, in press).

12) C.N. Gutta T. Oniub A. Mehrabia P. Schemmera A. Kashfib T. Krausa M.W. Büchlera. Circulatory and Respiratory Complications of Carbon Dioxide Insufflation. Dig Surg 2004;21:95-105

13) Nguyen NT, Lee SL, Goldman C, Fleming N, Arango A, McFall R, Wolfe BM: Comparison of pulmonary function and postoperative pain after laparoscopic versus open gastric bypass: A randomized trial. J Am Coll Surg 2001; 192:469-476; discussion 476-477.

14) Hideo Iwasaka, Hiroshi Miyakawa, Hitoshi Yamamoto, Takaaki Kitano, Kazuo Taniguchi, Natsuo Honda. Respiratory mechanics and arterial blood gases during and after laparoscopic cholecystectomy Canadian Journal of Anaesthesia 1996;43

15) Rauh R, Hemmerling TM, Rist M, Jacobi KE: Influence of pneumoperitoneum and patient positioning on respiratory systemcompliance. J Clin Anesth 2001; 13:361-365.

16) Struthers AD, Cuschieri A. Cardiovascular consequences of laparoscopic surgery. Lancet. 1998; 352:568-570. 